\title{
SPINAL CORD INJURY-A COST BENEFIT ANALYSIS OF ALTERNATIVE TREATMENT MODALS
}

By Professor Edgar D. Charles, Hospital and Health Administration, Professor Joseph G. Van Matre, School of Business, in collaboration with Professor John M. MILlER III, Department of Rehabilitation Medicine University of Alabama in Birmingham

\section{INTRODUCTION ${ }^{1}$}

SPINAL cord injury resulting in paraplegia or tetraplegia is the most devastating injury in medicine. Until as late as 1939,95 per cent of traumatic paraplegics and quadriplegics in the world died within five years after the accident. Since World War II well-run spinal cord centres in Europe and Australia have reversed this mortality trend during the first five years and the long-term survival rate of those patients who maintain a sterile urine has begun to approach a normal life span. In economic terms this has resulted in an unusual paradox. For spinal cord injury, the lower the mortality rate the higher the costs of the injury. This is because, in general, patients with spinal cord injuries incur high medical costs throughout their life spans (Wilcox, Stauffer \& Nickel, I970), lack of independence causes high attendant costs (or opportunity costs if a member of the family cares for the patient), and relatively few patients return to gainful employment.

With few exceptions hospitals in the United States have failed to implement fully an optimal spinal cord injury programme (Planning Conference for Comprehensive Spinal Cord Injuries Centers, 1968). This failure is primarily a result of the uncoordinated system of health care in the United States (Proceedings Conference Downey, I969). The typical patient is removed from the site of injury by people unqualified to provide excellent emergency medical treatment and moved to a general hospital. At that point the acute trauma is referred to a surgical specialty, highly skilled in neurosurgery and orthopaedic surgery, but frequently not familiar with long-term management of these patients. After four to six weeks at the acute general hospital, while the patient is in skeletal traction, the patient is transferred to a 'rehabilitation centre'. These centres must spend considerable time in correcting unnecessary complications (such as bed sores, contractures and urinary tract infections) created by inadequate management at the general hospital. But centres do not always adequately follow through with the rehabilitation programme in the patient's home community after discharge. Inadequate communication between the rehabilitation centre and vocational rehabilitation services has resulted in a poor employment rate.

In comparison to the United States approach, the rehabilitation centre in the European system accepts complete responsibility for the care of the patient from time of injury to complete rehabilitation or throughout life. The personnel at the rehabilitation centre are in complete control of the patient, who is transferred to

1 The authors wish to acknowledge the Social Rehabilitation Service for providing funds for this research (ORD-RD-P-5586214-03); Dr. John Miller, Director of the Spain Rehabilitation Center, for his explanations of the medical aspects of spinal cord injury; and Mr. Travis Wood, Director of Computer Services at the Spain Rehabilitation Center, for data processing. 
the rehabilitation centre as quickly as possible. At the National Injury Centre at Stoke Mandeville in England, 90 per cent of their patients arrive within 24 hours after injury. Specialised care by experts in the management of spinal cord injured patients has resulted in better bladder and bowel care (in the United States 60 per cent of these patients die directly or indirectly from renal complications, while at Stoke Mandeville 80 per cent of the patients are discharged with a reflex emptying bladder, catheter free with a sterile urine), far lower incidences of pyelonephritis, and higher rates of employment (Nyquist, I960; Guttmann \& Frankel, I966; Gibbon et al., I968; Walsh, I968).

\section{MULTIDISCIPLINARY SYSTEMS APPROACH}

In the early I970s the Social Rehabilitation Service, Department of.Health, Education, and Welfare and leading rehabilitation specialists in the United States became very concerned about the disparity between treatment of the spinal cord injured patient in the United States and Europe. The decision was made to fund seven rehabilitation centres to develop model regional systems of spinal cord rehabilitation. In addition to the Spain Center other model systems are: New York University, Institute of Rehabilitation Medicine, New York; Woodrow Wilson Rehabilitation Center and the University of Virginia, Fisherville, Virginia; Wesley Memorial Hospital and Rehabilitation Institute of Chicago, Chicago; Texas Institute of Rehabilitation and Research, Houston; Good Samaritan Hospital and St. Joseph's Hospital, Phoenix; and the Department of Rehabilitation Medicine, University of Washington, Seattle.

One of the centres selected was the Spain Rehabilitation Center, University of Alabama in Birmingham. At the Spain Center a multi-disciplinary team approach was developed which involves several medical specialties: physiatry, urology, neurosurgery, othopaedic surgery; extensive utilisation of paramedical disciplines such as physical therapy, occupational therapy, vocational counselling, social service, psychology, rehabilitation nursing, emergency medical services; and meticulous integration of the various community services (with frequently incompatible government services) and the return of the patient to his family and community.

The purpose of the grants was to establish in each region a system for the treatment of spinal cord injury. It should be recognised that, for the most part, all of the components of the systems approach were already in existence but they needed to be coordinated and tied together. In addition, a significant proportion of the funds was to be utilised to demonstrate the value of the systems approach medically and economically.

During the planning stages for the spinal cord centre the authors were requested to design a methodology for measuring the benefits of establishing the system. The economic analysis was only a small proportion of the project because the medical team wanted elaborate data on the medical results of the systems approach and also on specific procedures.

The following limitations of the economic analysis were immediately recognised.

I. A review of existing literature and data on costs of spinal cord injury revealed that reasonably accurate estimates of the cost of spinal cord injury were not available. 
2. The treatment of the spinal cord injured patient has undergone so many changes that historical cost data is not representative of the costs of more recently injured patients.

3. It would be very difficult to obtain a complete profile of medical and economic data about spinal cord injured patients who are not treated at spinal cord injury centres. The detailed information about the medical diagnosis and evaluation, and economic costs and follow-up data are not readily available unless an institution has made an extensive commitment to obtain the data.

4. Because of the limitations cited above (Proceedings Conference Downey, I969), the decision was made to utilise a somewhat arbitrary definition of a 'system' and 'non-system' patient. Patients who are referred to the rehabilitation centre within 30 days after onset of injury from an adequately staffed participating hospital are classified as 'system' patients. Patients who are referred after 30 days are considered 'non-system' patients as well as those referred from non-participating hospitals.

This definition presents analytical problems. This definition does not permit a comparison of the economic costs of the 'system' patient with the purely 'nonsystem' patient (who has undergone complete treatment and rehabilitation in a general hospital). What is being compared is the 'system' patients who have been in the system approach from the onset of injury to discharge from the rehabilitation centre to the patients who have not been in the system from onset to time of transfer to the rehabilitation centre and then optimum treatment at the rehabilitation centre. In other words, from the moment of admittance to the rehabilitation centre both the 'system' and 'non-system' patient receive the same quality of care.

5. Since there are four types of spinal cord injury with varying levels of lesion (paraplegia, tetraplegia; incomplete or complete), each spinal cord centre will have a small number of patients in each category which will present statistical difficulties. In addition, since each centre may collect different data, disagree on common definitions, have different cost reporting systems, etc., it may not be possible to collect comparable data.

6. Estimating indirect costs will present formidable analytical problems. Future medical and attendant costs are difficult to estimate as are lost earnings (especially whereas many spinal cord injuries occur in teenagers and young adults when educational and career objectives are unknown). Longitudinal studies are obviously required.

7. A large proportion of the data must be obtained from a variety of sources and will require the cooperation of many institutions, patients and families. Considering the seriousness of spinal cord injury and the psychological state of the patient this must be carefully approached.

8. The study will require the intense cooperation of both physicians and economists. At times the goals and objectives of each may conflict.

9. Finally, many of the benefits of improved patient care are intangibles which are impossible to convert to dollars, for example: pain and suffering, embarrassment, dependence upon family members, social activity, and psychological adjustment.

\section{LIMITATIONS OF PRESENT PAPER}

The above-enumerated items are limitations of the economic analysis in general; however, because the research project is only in the second year of a 
five-year study there are additional limitations of the paper which should be observed.

I. Since the project is only in the second year, there was the typical 'start-up' lag, and complete medical cost data can be compiled only after discharge, medical cost data is complete for only I 3 of the 'non-system' patients and 22 of the 'system' patients.

2. Although data are being collected on medical, attendant and environmental costs after discharge the number of follow-up interviews has not been adequate to draw any firm inferences.

\section{ESTIMATES OF THE COST OF SPINAL CORD INJURY}

Estimates of the cost of spinal cord injury have been made by physicians and representatives of insurance companies. However, these estimates did not utilise modern techniques of economic analysis.

Incidence. Although precise figures on the incidence of spinal cord injury are unavailable most experts believe the incidence in the United States to be around 25 per million of population (John Young, M.D.: Extracted from 1972 Grant Progress Report, SRS Grant No. RD3367-M-70. The Southwest Regional System for Treatment of Spinal Injury, Phoenix). This estimate was confirmed by a preliminary study of the incidence in Alabama which identified an incidence of 80 new cases per year which is equivalent to $22 \cdot 2$ per million of population (John Miller, M.D., Director, Spain Rehabilitation Center, University of Alabama Medical Center, Birmingham).

Cost. Mr. David Barrie estimated in I968 that Liberty Mutual Insurance Company of Boston paid out in Workman's Compensation $\$ 315,000$ to each traumatic paraplegia (Personal Communication between Mr. Dave Barrie of Liberty Mutual Insurance Company and Dr. John Miller of Spain Rehabilitation Center, Birmingham). Of course, Workman's Compensation payments are much lower than total economic costs. If we multiply Barrie's estimate by 80 new cases in Alabama, society's cost is estimated to be $\$ 25,264,000$. Considering the national level, if the incidence is 25 per million this would be approximately 5,000 new cases per year for a total of $\$ 1,575,000,000$.

Estimates of the cost of spinal cord injury have also been made by John Young, M.D., Project Director of the Southwest Regional System for Treatment of Spinal Injury in Pheonix. Based upon limited medical cost data from 30 patients and a large number of assumptions concerning long-run medical and indirect costs, Dr. Young computed the total costs to be $\$ 345,920$ for tetraplegics with complete or essentially complete paralysis and $\$ 178,840$ for paraplegics with complete or essentially complete paralysis.

Dr. Young also calculated the cost of initial hospitalisation to be $\$ 17,920$ for tetraplegics with complete or essentially complete paralysis and $\$ 14,840$ for paraplegics with complete or essentially complete paralysis.

To an economist the estimates by Barrie and Young suffer serious problems. For example, neither study adjusts for discounting and Dr. Young's study involves serious double counting. 


\section{ANALYSIS OF PATIENTS AT THE SPAIN REHABILITATION CENTER}

The previous sections of the paper have presented a brief discussion of the spinal cord injured patient, a discussion of the historical development of the 'systems' approach, definition of 'systems' and 'non-systems' patients, and a summary of previous estimates of the cost of spinal cord injury. This section presents a preliminary analysis of the cost savings of the 'systems' approach to the management of the spinal cord injured patient.

Costs of the 'Systems' Approach. The federal grant to the Spain Rehabilitation Center was for $\$ 250,000$ for each of five years. However, for a variety of reasons this is not necessarily the cost of the 'systems' approach. First, the majority of components of the system (i.e. general hospitals, a specialised rehabilitation centre, emergency medical services) were already in existence. When examining the total costs of the 'system' these costs must be considered. For example, if an underdeveloped country wished to construct and staff a 'system' these investments must be made. Second, a major part of the grant funds are being utilised for medical research and evaluation of alternative treatment procedures. In the judgment of the medical director of the Spain Rehabilitation Center approximately $\$ 60,000$ is required annually to bring together the separate components to form the 'system'. In one sense, this may be considered the marginal costs of transferring a 'non-system' into a 'system'. For purposes of this paper $\$ 60,000$ annually will be considered the cost of implementing and funding the 'system'.

Benefits. The tangible benefits resulting from the system approach can be classified into three categories:

I. Reduced medical costs from onset of injury until discharge from the rehabilitation centre.

2. Reduced medical and attendant costs after initial discharge.

3. Increased earnings.

Since this paper was prepared with only preliminary data available, only the reduction in medical costs from onset to initial discharge can be analysed. Although benefits relating to categories 2 and 3 are unavailable at this time, data for such analyses are being collected. This limitation will tend to underestimate the benefits because in the opinion of rehabilitation physicians the 'system' patient will undergo fewer complications during the initial hospitalisation which will result in fewer readmissions after initial discharge. It should be re-emphasised that the present analysis is concerned only with tangible benefits measured in dollar terms and there may be numerous intangible benefits.

\section{Benefit Cost Model}

$$
\text { Benefit } / \text { Cost ratio }=R=\frac{\bar{B}_{1}+\bar{B}_{2}+\bar{B}_{3}}{\bar{C}},
$$

where $\bar{B}_{1}=$ present value of savings in total medical costs for initial hospitalisation and

$$
\text { using systems approach }
$$




$$
\bar{B}_{1}=\sum_{i=1}^{5} B_{1 i}(1+r)^{i-1}
$$

where $\bar{B}_{1 i}=$ decrease in medical costs for all system patients in year $i$ (for 1974, $i=1$ )

$r=$ discount rate.

Assuming a comparable patient mix from year to year, it is hypothesised:

$$
B_{1 i}=K n_{i}+e_{i}
$$

where $K=$ cost savings per system patient

$n_{i}=$ number of system patients in year $i$

$e_{i}=$ error term for year $i$.

Now, $B_{2}=$ present value of savings in lifetime medical costs (excludes initial hospitalisation) using systems approach and

$$
\bar{B}_{2}=\sum_{j=1}^{50} \sum_{i=1}^{5} B_{2 i j}(1+r)^{i+j-1}
$$

where $\mathrm{B}_{2 i j}=$ net decrease in medical costs in $j$ th year following discharge for systems patients hospitalised in year $i$.

Assuming a comparable patient mix and a comparable survival rate for systems and non-systems patients, it is hypothesised:

$$
\begin{aligned}
B_{2 i j} & =n_{i j} S_{j}+e_{i j} \\
& =n_{i} \alpha_{j} S_{j}+e_{i j},
\end{aligned}
$$

where $n_{i j}=$ number of surviving system patients in year $j$ th following their injury in year $i$

$n_{i}=$ number of system patients in year $i$

$\alpha_{j}=$ survival rate in $j$ th year following injury

$S_{j}=$ savings in medical costs per system patient in the $j$ th year

$e_{i j}=$ error term.

Then, $\bar{B}_{3}=$ present value of increased earnings for systems patients and

$$
\bar{B}_{3}=\sum_{j=1}^{50} \sum_{i=1}^{5} B_{3 i j}(1+r)^{i+j-1}
$$

where $\mathrm{B}_{3 i j}=$ net increase in earnings in the $j$ th year following discharge of system patients hospitalised in year $i$.

Assuming comparable patient mixes and survival rates for system and nonsystem patients through time,

$$
\begin{aligned}
B_{3 i j} & =n_{i j} I_{j}+e_{i j} \\
& =n_{i} \alpha_{j} I_{j}+e_{i j},
\end{aligned}
$$

where $I_{j}=$ average income differential between system and non-system patient in $j$ th year following discharge

$n_{i}=$ number of system patients in year $i$

$\alpha_{j}=$ survival rate in $j$ th year following injury

Finally,

$e_{i j}=$ error term.

$$
C=\sum_{i=1}^{5} C_{i}(1+r)^{i-1} \quad i=1, \ldots, 5
$$

where $C_{i}=$ cost of the system in the $i$ th year. 
Hence:

$R=\frac{B}{C}=\frac{\sum_{i=1}^{5} B_{1 i}(1+r)^{i-1}+\sum_{j=1}^{50} \sum_{i=1}^{5} B_{2 i j}(1+r)^{i+j-1}+\sum_{j=1}^{50} \sum_{i=1}^{5} B_{3 i j}(1+r)^{i+j-1}}{\sum_{i=1}^{5} C_{i}(1+r)^{i-1}}$.

Table I presents the mean lengths of stay for 'system' and 'non-system' patients. The reduction in length of stay has both tangible and intangible benefits.

TABLE I

Mean number of days for 'systems' $v$ s. 'non-system' patienttotal, receiving hospital, and Spain Rehabilitation Center

\begin{tabular}{|c|c|c|}
\hline Total & System & Non-system \\
\hline $\begin{array}{c}\text { Mean days } \\
\text { Onset to discharge } \\
\text { Mean days } \\
\text { In receiving hospital } \\
\begin{array}{c}\text { Mean days } \\
\text { In Spain Rehabilitation Center }\end{array}\end{array}$ & 86.91 & 166.00 \\
\hline
\end{tabular}

Tangible economic benefits should be reflected in a reduction in costs and intangible psychological benefits should result from more time spent with the family and home community (Klarman, 1965; Rice, 1969).

In order to make meaningful inferences concerning medical costs, differences between 'system' and 'non-system' patients, the patient 'mix' within the groups

\section{TABLE II}

Distribution of patient mix: system vs. non-system

\begin{tabular}{|l|c|c|c|c|c|c|}
\hline & $\begin{array}{c}\text { Quadri- } \\
\text { plegic } \\
\text { complete }\end{array}$ & $\begin{array}{c}\text { Quadri- } \\
\text { plegic } \\
\text { incomplete }\end{array}$ & $\begin{array}{c}\text { Paraplegic } \\
\text { complete }\end{array}$ & $\begin{array}{c}\text { Paraplegic } \\
\text { incomplete }\end{array}$ & Total & $\begin{array}{c}\text { Average } \\
\text { age }\end{array}$ \\
\hline System & 6 & 8 & 5 & 3 & 22 & $29 \cdot 8$ \\
Non-system & 3 & 5 & 3 & 2 & 13 & $30 \cdot 2$ \\
\hline
\end{tabular}

must be substantially the same. Table II demonstrates that the patient 'mix' and age is substantially the same. As more data become available appropriate statistical tests concerning patient mix will be performed.

Mean medical charges are presented in Table III. A mean difference of $\$ 6,067$ is observed between the medical costs for the 'system' and 'non-system' 
patient. The hypothesis that this difference could arise through chance variation is rejected at a significance level of 0.10 . Additional data is presented in the appendix.

\section{TABLE III}

Mean charges by physicians and hospitals-total, prior to Spain, Spain Rehabilitation Center, system vs. non-system

\begin{tabular}{|l|r|r|}
\hline & System & Non-system \\
\hline Total & I0,972 & I7,039 \\
Prior to Spain & 3,538 & 8,723 \\
Spain Rehabilitation Center & 7,434 & 8,316 \\
\hline
\end{tabular}

\section{Preliminary Estimates}

where

$$
R=\frac{\bar{B}_{1}+\bar{B}_{2}+\bar{B}_{3}}{\bar{C}}
$$

$$
\bar{B}_{1}=\sum_{i=1}^{5} B_{1 i}(1+r)^{i-1}
$$

and assuming a comparable patient mix and an equal number of system patients per year:

$$
B_{1 i}=n K+e_{i}
$$

and using current, preliminary estimates of 60 system patients per year and cost savings of $\$ 6,067$ per patient (see Table III)

$$
B_{1 i}=60(6,067)=364,020 \text {. }
$$

Then, discounting at a 6 per cent rate,

$$
\begin{aligned}
\bar{B}_{1} & =\sum_{i=1}^{5} 364,020(1+0 \cdot 06)^{i-1} \\
& =1,625,349 \cdot 30 .
\end{aligned}
$$

Since no data is available for estimating $\bar{B}_{2}$ or $B_{3}$ for the moment they shall be ignored i.e. assumed to be negligible.

$$
\bar{C}=\sum_{i=1}^{5} C_{i}(1+r)^{i-1}
$$

and $C_{i}=60,000$, for all $i$ (see page 227) then

$$
\bar{C}=\sum_{i=1}^{5} 60,000 \quad(1+0 \cdot 06)^{i-1}=267,900 .
$$


Then, a tentative estimate of the $B-C$ ratio is:

$$
R=\frac{1,625,349 \cdot 30}{267,900}=6 \cdot 07 .
$$

\section{SUMMARY AND CONCLUSIONS}

This paper has presented a preliminary estimate of the benefits of a 'systems' approach to the treatment of spinal cord injury. The preliminary cost-benefit ratio exceeds six. For a variety of reasons, this is probably a severe underestimate of the benefits because possible reductions in medical and attendant costs after discharge have not been included nor have any potential increase in earnings. In addition, the definition of 'system' and 'non-system' patients also tends to underestimate the benefits.

The accumulation of follow-up data will permit an estimate of post-discharge medical and attendant costs and increase in earnings. A large number of patients will also permit additional statistical analysis.

\section{REFERENCES}

Attending Staff Association of the Rancho Los Amigos Hospital (1969). Proceedings, Downey, California, October.

Gibbon, N. O. K., Ross, J. Cosbie \& Silver, J. R. (1968). Changes in the upper urinary tract following various types of initial treatments. Paraplegia, 7, 63-7I.

GutTMANN, L. \& FrANKEL, H. (I966). The value of intermittent catherization in the early management of traumatic paraplegia and tetraplegia. Paraplegia, 4, 63-84.

KlaAman, Herbert E. (I965). Syphilis control programs. Measuring Benefits of Government Investments, p. 370.

Nyquist, R. H. (I960). Proceedings of the Ninth Annual Spinal Cord Injury Conference. P. I09. Proceedings of Planning Conference of Comprehensive Spinal Cord Injury Centres (I968). Downey, California. Nov. 25-26.

Rice, Dorothy P. (I969). Measurement and application of illness cost. Public Health Reports, 84, p. 370.

Walsh, J. J. (1968). Further experience with intermittent catherization. Paraplegia, 4, 74-78.

Wilcox, N. E., Stauffer, E. Shannon \& Nickel, Vernon L. (I970). A statistical analysis of 423 consecutive patients. Paraplegia, 8, 27-35.

\section{APPENDIX}

\section{TABLE IV}

Mean of total charges by classification of spinal cord injurysystem vs. non-system

\begin{tabular}{|l|c|c|} 
& System & Non-system \\
\hline Tetraplegic-complete & I2,227 & 20,469 \\
Tetraplegic-incomplete & I0,09I & I6,982 \\
Paraplegic-complete & I0,926 & I3,948 \\
Paraplegic-incomplete & I0,895 & 21,244 \\
\hline
\end{tabular}


TABLE V

Mean of hospital charges by classification of spinal cord injurysystem $v$ s. non-system

\begin{tabular}{|l|c|c|} 
& System & Non-system \\
\hline Tetraplegic-complete & I I,228 & I 8,808 \\
Tetraplegic-incomplete & 8,914 & I 5,26I \\
Paraplegic-complete & 9,238 & I2,540 \\
Paraplegic-incomplete & 9,623 & I8,66I \\
\hline
\end{tabular}

\section{TABLE VI}

Mean charges, Spain Rehabilitation Center and totalsystem $v$ s. non-system

\begin{tabular}{|c|c|c|}
\hline & System & Non-system \\
\hline Mean: & & \\
Prior to Spain & 2,565 & 7,249 \\
Mean: & & 8,022 \\
Spain Rehabilitation Center charge & $7,15 \mathrm{I}$ & \\
Mean: & 9,716 & $15,27 \mathrm{I}$ \\
$\quad$ Total charge & & \\
\hline
\end{tabular}

\section{TABLE VII}

Mean physician charges-system vs. non-system

\begin{tabular}{|l|r|r|} 
& System & Non-system \\
\hline $\begin{array}{l}\text { Mean physician charges: } \\
\text { Prior to Spain }\end{array}$ & 973 & 1,474 \\
$\begin{array}{l}\text { Mean physician charges: } \\
\text { Spain Rehabilitation Center } \\
\text { Mean physician charges: } \\
\text { Onset to discharge }\end{array}$ & 283 & 294 \\
\hline
\end{tabular}

